UNIO - EU Law Journal. Vol. 4, No. 1, January 2018, pp 78-101.

®2018 Centre of Studies in European Union Law

School of Law - University of Minho

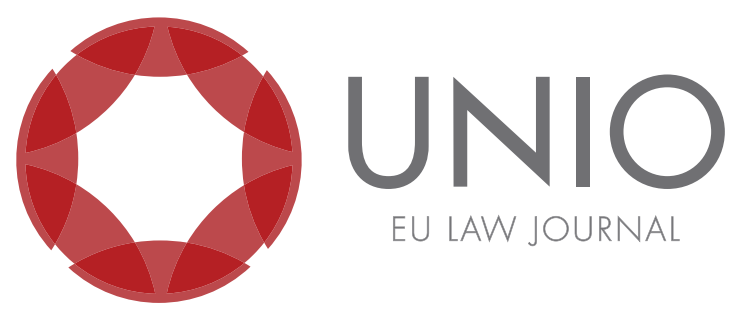

\title{
Information exchanges between competitors from a competition law perspective - the problem of premature exchanges of sensitive information in the context of merger control (Gun Jumping)
}

\author{
Nuno Calaim Lourenço*
}

ABSTRACT: The topic of information exchanges between competing undertakings is central to competition law. These are practices that enhance market transparency and, as such, can generate significant efficiencies. However, they can also give rise to serious competition concerns, often because they afford competitors the possibility of reaching focal points of coordination. The analysis of information exchanges has traditionally taken place in the context of the legal framework that probibits cartels. This article reviews, at first, the approach taken in Europe by competition authorities and courts, firmly grounded in the Commission Guidelines and in the most recent case law of the European Court of Justice. After discussing the relevant legal framework and the main criteria for the assessment of information exchanges in detail, the article elaborates on the specific problem that premature exchanges of information between competitors can create in the context of a merger transaction. As the competitors that they are, at least until closing of the deal, it is essential that contracting parties ensure that their due diligence exercise and the planning of the integration of their businesses are carried out in a manner that is consistent with competition rules, avoiding behaviour that can be interpreted as gun-jumping or as a cartel practice and, as a consequence, financial penalties and judicial claims.

KEYWORDS: competition - information exchanges - cartel - mergers - Gun Jumping.

\footnotetext{
* Managing Associate at SRS - Sociedade Rebelo de Sousa \& Advogados Associados, R.L., in the Competition and EU Law Department. Previously he has worked as an agent at the Directorate-General for Competition in the European Commission and as a Solicitor in the Competition Department at White \& Case LLP, in Brussels. Graduate in Law from the Law Faculty of the University of Lisbon (1999) and a Post-Graduate in Legal Sciences from the Catholic University of Lisbon (2001). He has obtained a LLM degree (Master of Laws) in Competition Law at Queen Mary University of London (2010), and a Master's degree in EU and Competition Law at the Law Faculty of the University of Lisbon (2012).
} 


\section{Introduction}

On 14 December 2010, the European Commission (hereinafter "the Commission") adopted a revised version of its Guidelines for the assessment of cooperation agreements between competitors from a competition law point of view. ${ }^{1}$ The document comes as a result of a relatively protracted reform process that included two public consultations (held in December 2008 and in April 2010) and aroused the interest of the business community, both within and outside of the European Union ("EU"). ${ }^{2}$

A principle new feature of the document is the guidance it offers regarding the issue of information exchanges between competitors. ${ }^{3}$ The Guidelines constitute the Commission's first attempt at establishing more detailed rules of general application in an area of law which has hitherto been characterised by scant and unclear case-law and decision-making practice. ${ }^{4}$ The Guidelines, as well as some of the more recent decisions adopted by European national competition authorities, reflect a renewed interest in the analysis of information exchanges and the adoption of a somewhat stricter approach.

The purpose of this article is twofold. We propose at the outset (Chapter I) to review the general principles which the Commission explores in its Guidelines, ${ }^{5}$ which have been applied by courts and competition authorities since their adoption. Our aim is to identify the main competition concerns presented by information exchanges and the types of information exchanges that may be caught by competition law. We will also discuss the main criteria used in the assessment of information exchanges, taking into account the precedents set by the decision-making practice and case-law that have most contributed to the interpretation and integration of the regime. In the second part (Chapter II), having clarified the relevant legal framework, the article applies its principles and rules of analysis, in a more pragmatic approach, in relation to situations of information exchanges between competitors in an M\&A context, prior to the final clearing decision by the competition authority, the Commission or the Portuguese Competition Authority ("PCA"). As competitors, it is essential that the contracting parties to such a transaction ensure that their due diligence démarches and integration planning are carried out in accordance with the prescribed competition rules, in both the EU and in Portugal. ${ }^{6}$

So-called 'Gun Jumping' behaviour, particularly in terms of the exchange of strategic and sensitive information by the contracting parties to a merger, may be interpreted by the Commission or by the PCA as a violation of competition law (such

\footnotetext{
${ }^{1}$ Guidelines on the applicability of Article 101 of the Treaty on the Functioning of the European Union to horizontal cooperation agreements, OJ C 11/1 of 14.01.2011 (hereinafter "the Guidelines"). ${ }^{2}$ At the end of its 2010 public consultation process, the Commission had already received more than 100 submissions, including submissions from two Japanese organizations (Japan Electronics \& Information Technology Industries Association and Japan Business Council in Europe).

${ }^{3}$ The other main novelty, which goes beyond the scope of this article, relates to the detailed rules that the document proposes with respect to standard setting.

${ }^{4}$ The only official document, of an earlier date, in which the Commission dealt with the issue of information exchanges was the Guidelines on the application of Article 81 of the EC Treaty to maritime transport services, OJ C 245/02, of 26.9.2008.

${ }^{5}$ Which seek to offer guidance based on jurisprudence and precedents stemming from Judgments of the Court of Justice of the European Union (CJEU) which have dealt with these matters.

${ }^{6}$ Competition law in Portugal, laid out primarily in Law 19/2012, of May 8 (hereinafter "Portuguese Competition Act"), provides for specific features of regulation vis-à-vis the framework set in the TFEU. However, with regard, in particular, to the criteria used in the assessment of cooperation agreements between competitors, the decisional practice of the PCA applies the Guidelines and, as such, conclusions drawn from that document are fully applicable in the application of national law.
} 
as a violation of the standstill obligation imposed before the merger is cleared and/or as collusive behaviour which could be regarded as a cartel practice), potentially exposing the parties to fines and the right of third parties to be indemnified in the context of compensatory judicial actions. ${ }^{7}$ In the second chapter of this article we set forth the rules that should govern how the contracting parties can safely conduct commercial operations between the signing and closing of the deal. We will see that the same principles of analysis must be applied in the preliminary phase, during negotiations before the contract is formalized, and in some cases, ex post, after the transaction has been cleared by the competition authority and implemented.

\section{Information exchanges in general - analysis of the legal framework}

\section{Competition concerns presented by information exchanges}

Competition law does not prevent companies from strategically adapting their market conduct to that pursued by their competitors or to that which they are likely to pursue in the foreseeable future. However, it must be determined autonomously and independently. Competition law prohibits any direct or indirect contact between competitors that reduces, or is likely to reduce, their strategic independence (and hence the strategic uncertainty associated with market intervention) and their incentives to compete on a meritocratic basis. ${ }^{8}$

There are two main competition concerns in relation to information exchanges. Firstly, the exchange of so-called "strategic" information, such as information on prices, volumes or capacities, artificially increases transparency in the market, providing companies with information they would not otherwise be able to obtain. This increased transparency can facilitate collusive behaviour, as competitors can reach strategic focal points of concertation much easier - agreeing on the main parameters of competition to be manipulated and the terms of alignment of their commercial behaviours in the market - and to arrive at a common understanding as to how the market structure and dynamics should evolve in the immediate future. ${ }^{9}$ It also facilitates the process of monitoring the behaviour of competitors with the objective of verifying that all parties

\footnotetext{
${ }^{7}$ As occurred, as we will see further on, with regard to the Commission's investigation, in 2007, in case COMP/M.4734, involving the companies Ineos and Kerling.

${ }^{8}$ See, inter alia, the Judgment of the Court of Justice of 16 December 1975 in Joined Cases 40 to 48, 50, 54 to 56, 111, 113 and 114-73, Coöperatieve Vereniging "Suiker Unie" UA and others v. Commission of the European Communities, ECLI:EU:C:1975:174, para. 173; Judgment of the Court of Justice of 14 July 1981 in Case C-172/80, Gerhard Züchner v. Bayerische Vereinsbank AG, ECLI:EU:C:1981:178, para. 14; Judgment of the Court of 28 May 1998 in Case C-7/95 P, John Deere Ltd v. Commission of the European Communities, ECLI:EU:C:1998:256, para. 86.

${ }^{9}$ See in this regard Margaret C. Levenstein and Valerie Y. Suslow, "Cartel bargaining and monitoring: The role of information sharing" in The Pros and Cons of information Sharing, Swedish Competition Authority (Stockholm: Lenanders Grafiska AB, 2006), 44: "In almost all cases where collusion is feasible, there are multiple possible collusive equilibria. If all firms rank these various equilibria in the same preference order, then it is reasonable to presume (though not a foregone conclusion) that they will each select the best possible equilibria. In most cases, however, firms will have different rankings among possible equilibria, requiring some form of communication in order to move them toward an efficient equilibrium. If firms are probibited by antitrust authorities from communicating, they may use focal points to choose among the multiple equilibria. For example, firms colluding tacitly without direct communication may use public price announcements or other forms of indirect communication to reduce uncertainty regarding the appropriate market price".
} 
involved are complying with the (illicit) agreement that is intended to be implemented. ${ }^{10}$ In this context, the exchange may also allow cartelists to adopt market behaviours that are strategically oriented to prevent potential competitors from entering the market or to frustrate new entrants (i.e. closing the market to operators who might compromise the cartel). ${ }^{1112}$

Secondly, the exchange of strategic information may have exclusionary effects when it places non-participating competitors in a position of significant competitive disadvantage. However, the Commission notes that this type of effect "is only possible if the information in question is of strategic importance in terms of competition and covers a significant part of the relevant markeet'. ${ }^{13}$ Consider, by way of example, an industry-wide database which records the historical behaviour of customers in terms of accidents or contractual non-compliance: to deny an insurer, in particular, access to that database would have the effect of placing it in a position of significant competitive disadvantage vis-à-vis its competitors. ${ }^{14}$

${ }^{10}$ Companies involved in coordination should be able to monitor whether the conditions of coordination are being met. There should be credible deterrents that can be activated when a deviation from the established coordination is detected. If coordination cannot be monitored effectively, it either ends or it will only be permitted at a price close to the competitive price. This premise was articulated for the first time by George Stigler in his work, The Organisation of Industry, (London: University of Chicago Press, 1968), 42: "If the enforcement is weak, however - if price cutting is detected only slowly and incompletely - the conspiracy must recognise its weakness: it must set prices not much above the competitive level so the inducements to price-cutting are small, or it must restrict the conspiracy to areas in which enforcement can be made efficient'.

${ }^{11}$ Thereby strengthening the external stability of the cartel. For an analysis on the subject of external stability in the context of coordinated effects on mergers, see the joint publication of the Office of Fair Trading and the Competition Commission, Review of Merger Assessment Guidelines, 2010, p. 41. The existence in the market of a sufficient number of undertakings not covered by the collusive agreement constitutes a risk to the subsistence of the latter, since these outsiders will be able to practice comparatively more favorable prices/trading conditions and divert a substantial amount of demand - thereby depriving cartelists of scale and reducing their incentive to continue to comply with the terms of the coordination. The exchange of information enables new entrants to be identified and to coordinate an adequate response, thereby enhancing the external stability of the cartel. In its decision in UK Tractors (Decision 92/157/EEC of 17 February 1992 - IV/31.370 and 31.446), the Commission made specific reference to these dynamics.

${ }^{12}$ Readers who are more familiar with the criteria for substantive merger analysis will note the similarity between the Airtours Judgment criteria for the assessment coordinated effects that may result from a merger and the criteria proposed by the Guidelines for analysing the impact of information exchanges on coordinated effects. See Judgment of the Court of First Instance of 6 June 2002 in Case T-342/99 Airtours plc c. Commission of the European Communities, ECLI:EU:T:2002:146, para. 61 and ff.

${ }^{13}$ Cf. para. 70 of the Guidelines.

${ }^{14}$ Decision-making practice and case-law do not provide unambiguous examples of information exchanges that have resulted in the effective exclusion of competitors. However, there is a record of precedents in which competition authorities expressed concern that, alongside the collusive risk, the exchange could generate exclusionary effects. That was the case in the Commission's decision of 17 February 1992 in UK Tractors (IV/31.370 and 31.446) and in the Provvedimento n ${ }^{\circ} .13269$ of the Italian Competition Authority, of 10 June 2004 (Bollettino of 24/2004), in which it was held that the exchange system notified by Philip Morris to this Authority, according to which its retailers would be obliged to divulge to Philip Morris, on a monthly and exclusive basis, their aggregate daily sales volumes and the value of daily sales of competing brands cigarettes, was illegal. The Italian Authority considered that the obligation to report on competing cigarette sales would go beyond what would be strictly necessary for Philip Morris to supervise its business. From the point of view of the potential for the exclusion of its competitors, the Authority considered that the adoption of an exclusivity clause such as the proposed one would have the effect of preventing Philip Morris' competitors from having access to a similar set of retailers providing the same type of information. 
However, exchanges of information may also have pro-competition effects. ${ }^{15}$ The exchange may, for example, provide market operators with a better understanding of the market and the demand structure. Consumers, on the other hand, can benefit from enhanced transparency in relation to trading conditions, including prices (e.g. when the market players divulge this information through publications or third-party databases) - thereby reducing search costs and ensuring that the companies providing the best offer capture the largest market share ${ }^{16}$ - with the exchange potentially even allowing the detection of collusive schemes. Increased transparency can also help to facilitate the entry of new players; to provide a better and more credible prognostic analysis of market demand (creating allocative efficiencies) ${ }^{17}$ or to allow companies to compare their market performance (so-called "Benchmarking"). In certain markets, such as credit markets, exchanges of information may also allow operation to take place more efficiently by way of neutralizing information asymmetries. ${ }^{18}$

\section{Types of information exchanges covered by competition law}

According to the Guidelines, all types of information exchanges amongst competitors, whether direct or indirect, potentially fall within the scope of Article 101 TFEU, which prohibits agreements and concerted practices that restrict competition in the EU.

\subsection{Ancillary information exchanges}

Information exchanges which take place in the context of other horizontal cooperation agreements will be assessed in conjunction with the analysis of the main agreements. ${ }^{19}$ An information exchange intended to facilitate the creation or maintenance of a cartel (e.g. fixing prices or quantities) will obviously be considered to be unlawful and consequently treated as a cartel practice. In contrast, if the main agreement is lawful, for example in the wider context of cooperation agreements aimed at achieving efficiencies such as joint ventures or standardization or R\&D agreements, so too will be the ancillary information exchanges, so long as they do not exceed "what

\footnotetext{
${ }^{15}$ Cf. para. 57 of the Commission's Guidelines; OECD, Information Exchanges Between Competitors under Competition Law, 2010, Executive Summary, 10.

${ }^{16}$ Diamond has shown that when it is excessively burdensome for consumers to seek the product they wish under conditions they want, the best response from companies is to charge monopoly prices for those products. Cf. Peter A. Diamond, "A Model of Price Adjustment" in Journal of Economic Theory $3, n^{\circ} .2$ (June 1971): 156-168.

${ }^{17}$ Ensuring that resources are allocated to those who want them most or need them most. Better information on demand can also create cost efficiencies allowing companies to reduce inventory. On the other hand, a company that only has information on its own level of demand may not be able to differentiate between deviations in the general demand on the market and deviations in its own demand.

${ }^{18}$ In the Asnef-Equifax case, for example, the information exchanged on the solvency of potential borrowers allowed credit institutions to reduce credit risk by mitigating the disparity between the information available to credit institutions and that which was held by potential borrowers. The Court of Justice considered that the system of information exchange implemented made it possible to reduce the number of defaulting borrowers and thus to improve the functioning of the whole market for lending, representing an added value in terms of economic efficiency. The exchange analysed did not restrict competition by object. Cf. Judgment of the Court of Justice of 23 November 2006 in Case C-238/05, Asnef-Equifax, Information Services on Solvency and Credit, SL v. the Association of Banking Services Users (Ausbanc), ECLI:EU:C:2006:734, para. 4.

${ }^{19}$ Cf. para. 56 of the Guidelines.
} 
is necessary" for the implementation of the agreement to which they relate. ${ }^{2021}$ For example, the legality of an information exchange regarding capacity parameters in the context of a joint marketing agreement will depend primarily on the legality of the marketing agreement itself.

Stand-alone information exchanges (isolated information exchanges that only occur once) are usually the most complex to analyse. In the past, in order for an information exchange to be considered an infringement by object, it was necessary for the exchange to be frequent. See, for example, the position of the Office of Fair Trading (OFT) in its decision in the Independent Schools case, considering that the information in question on the future fees to be collected by the various schools involved had been exchanged on a regular and systematic basis and that, as such, the exchange constituted an infringement by object. ${ }^{22}$ However, in a moment of an apparent shift in approach to the relevant legal doctrine, the Judgment of the Court of Justice in T-Mobile Netherland affirmed that, even if the exchange of information on future price intentions is not frequent and systematic, this does not exclude the possibility of it being considered an infringement by object. A single meeting between competitors, in which future prices are discussed, can constitute a sufficient basis for such an imputation. ${ }^{23}$

\subsection{Direct and indirect information exchanges}

Isolated information exchanges, as well as indirect information exchanges through third parties - through market research organisations, trade associations or any other third party - are scrutinized under the same criteria as direct information exchanges between competitors (see point 3 below). Indeed, one of the most notorious EU precedents on information exchanges involved an information exchange which was managed by a trade association (the entity which received and controlled the entire flow of sensitive and strategic information transmitted by its associate members) and provided its members with regular information on retail sales volumes and market shares of eight manufacturers and importers of agricultural tractors in the United Kingdom. ${ }^{24}$

Competition law also applies to so-called "hub-and-spoke" schemes, where strategic information is exchanged via common suppliers or retailers. ${ }^{25}$ Despite the

\footnotetext{
${ }^{20}$ Cf. paras. 56 to 59 , inclusive, and 88 of the Guidelines.

${ }^{21}$ The Commission's Fatty Acids decision (OJ 1987 L 3/17) is the first example of a ban on an information exchange system which was not ancillary to identified anti-competitive conduct but was nevertheless considered in itself to be in breach of competition law.

${ }^{22}$ Cf. OFT case CA98/05/2006, Private Schools: exchange of information on future fees [2006].

${ }^{23}$ See Judgment of the Court of Justice in Case C-8/08, T-Mobile Netherlands BV, KPN Mobile NV, Orange Nederland NV and Vodafone Libertel NV v. Raad van Bestuur van de Nederlandse Mededingingsautoriteit, ECLI:EU:C:2009:343, para. 59.

${ }^{24}$ See Commission decision of 17 February 1992 in Cases IV/31.370 and 31.446 - UK agricultural tractor registration exchange, OJ L 68/19, 13.03.1992. See Judgment of the Court of Justice of 28 May 1998 in Case C-7/95 P, John Deere Ltd v. Commission, ECLI:EU:C:1998:256.

${ }^{25}$ The hub-and-spoke concept/metaphor originates in the United States jurisprudence of the 40s to 60s, in precedents such as the Interstate Circuit v. United States, 306 U.S. 208 (1939); United States v. Masonite Corp., 316 U.S. 265 (1942); Klor's, Inc. v. Broadway-Hale Stores, Inc., 359 U.S. 207 (1959); United States v. Parke, Davis \& Co., 362 U.S. 29 (1960) and United States v. Gen. Motors Corp., 384, U.S. 127 (1966). The current US approach to hub-and-spoke will draw much of its rationale from the following jurisprudence: Toys "R" Us, Inc. v. FTC (TRU), 221 F.3d 928, 934-36 (7 $7^{\text {th }}$ Cir. 2000); PepsiCo, Inc. v. Coca-Cola Co., 315 F.3d 101, 109-11 (2d Cir. 2002); Dickson v. Microsoft Corp., 309 F.3d 193, 203-05 (4 ${ }^{\text {th }}$ Cir. 2002) and Guitar Center, 798 F.3d (2015). For an analysis see Barak Orbach, "Hub-and-Spoke Conspiracies", The Antitrust Source 15, no. 3 (April 2016), www.antitrustsource.com.
} 
dynamic and ever-evolving nature of the Commission's approach, for a considerable period of time, companies could rely on two relatively stable premises: (i) that vertical collection of information - collection and exchange of information between companies at different levels of the distribution/production chain - was not anti-competitive and would therefore be unlikely to give rise to scrutiny under competition law; and (ii) that, if they did not have a dominant position in the relevant market, their unilateral conduct would not infringe competition law. These premises have been questioned in Europe in recent years - particularly as a result of the emergence of doctrines such as bub-and-spoke and unilateral price signaling - as part of an attempt by European competition authorities to better define the notion of a "cartel". Unfortunately, the Guidelines are unclear as to the specific conditions for these schemes to fall within the scope of Article 101 of the TFEU and, consequently, of Article 9 of the Portuguese Competition Act. The most useful guidance is still to be found in the precedents of European decision-making and case-law.

In October 2006, in the United Kingdom, the Court of Appeals found, in two separate cases joined at the appeal stage (the Argos case), that Umbro (in Football Shirts) and Hasbro (in Toys and Games) had acted as intermediary vehicles in an anti-competitive practice aimed at exchanging information between retailers of, respectively, replicas of football shirts and Hasbro toys. In both cases, the retailers would inform their manufacturers of the retail pricing policies they intended to implement (e.g. not to sell below certain agreed price thresholds), and the manufacturers would, in turn, forward this information to other retailers. The Court considered that the following conditions should be met in order to find an infringement in such bub-and-spoke relationships (observing that illegality would be easier to establish if immediate reciprocity had been proven):

i) Retailer A discloses its future price intentions to supplier B in circumstances where A may be taken to intend that B will make use of that information to influence market conditions by passing that information to other retailers (among which is included retailer $\mathrm{C}$ );

ii) Supplier B does, in fact, pass this information to retailer $C$ in circumstances where $\mathrm{C}$ may be taken to know the circumstances in which the information was disclosed by A to B;

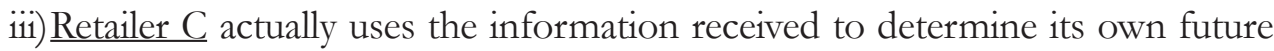
price intentions. ${ }^{26}$

According to this case-law, information exchanges within the scope of a huband-spoke relationships only infringe competition law when: (i) all parties involved have anti-competitive intentions, i.e. an intention to influence the market behaviour of competitors; (ii) the information exchanged is strategic; and (iii) the strategic information exchanged is used by the recipient to determine their market behaviour. ${ }^{27}$

Despite the doctrine in the aforementioned precedents, the Guidelines appear to have taken a more restrictive approach. According to paragraph 61, competition law precludes "any direct or indirect contact between operators which has as its aim or effect either to influence the market behaviour of an actual or potential competitor or to disclose to that competitor

\footnotetext{
${ }^{26}$ Cf. Argos and Littlewoods v. OFT and JJB v. OFT [2006] EWCA Civ. 1318, para. 141.

${ }^{27}$ Cf. Argos and Littlewoods v. OFT and JJB v. OFT [2006] EWCA Civ. 1318. In view of similarities in the legal issues raised by the appeals, the court eventually produced a joint Judgment concerning the decisions in crisis arising from the two separate investigations, the Replica Kits case and the Toys and Games case.
} 
the market behaviour that an operator has decided to adopt or intends to adopt, as such facilitating the adoption of collusive conduct within the market'. As can be seen, the Guidelines do not appear to require proof of anti-competitive intent. Furthermore, the third condition laid down by the Appeals Court, which concerns the causal link with subsequent market conduct, need not even be demonstrated since the European Court of Justice has already held in T-Mobile that "it must be assumed ... that companies participating in the concertation and still active in the market respond to the information exchanged with their competitors to determine their behaviour in that market" ${ }^{28}$

This understanding has been corroborated in the most recent jurisprudence of the CJEU, where Treuband ${ }^{29}$ is an illustrative example. AC Treuband is a Swiss consulting firm that is dedicated, among other activities, to the management and administration of professional associations, federations and non-profit organisations and to the collection, processing and commercial trading of market data. The Commission considered that $A C$ Treuband had played a key role in organising and conducting meetings between participants in a cartel which it had detected in the thermal stabilizer industry. The company had precise knowledge of the terms of the prohibited agreements and would even develop and professionally disseminate all the information regarding prices, quotas and customers. It was also in charge of auditing the activities of all members of the cartel. The Commission also found that the cartelists could only negotiate between themselves on the basis of information previously validated by $A C$ Treuband, and that the company provided the means and infrastructure to that end, always endeavouring to conceal the cartel. The Commission considered its involvement to be that of a cartel facilitator, and, as a cartelist party, it was fined $€ 174,000 .^{30}$ In its ruling, the General Court held "that it is sufficient for the Commission to show that the party in question had participated in meetings during which anti-competitive agreements had been carried out, without the party clearly opposing them, in order that the requisite legal standard be met to prove the party's participation in the cartel'. ${ }^{31}$

The approach of the Commission and the courts is subject to criticism because it risks scrutinizing exchanges of information that are legitimate and occur in the course of normal business relationships between suppliers and customers. It is thus submitted that, with regard to concerted practices, bub-and-spoke schemes should only be prohibited if the competition authority is able to establish: (i) a meeting of minds between the parties involved; and (ii) an appreciable effect on the conditions of competition within the market.

\subsection{Unilateral information exchanges}

According to the Commission, the unilateral disclosure of strategic information (without any form of reciprocity) may also be perceived to be an anti-competitive

\footnotetext{
${ }^{28}$ See Judgment of the Court of Justice in Case C-8/08, T-Mobile Netherlands BV, KPN Mobile NV, Orange Nederland NV and Vodafone Libertel NV v. Raad van Bestuur van de Nederlandse Mededingingsautoriteit, ECLI:EU:C:2009:343, para. 51.

${ }^{29}$ Judgment of the General Court of 6 February 2014 in Case T-27/10, AC-Treuhand AGv European Commission, ECLI:EU:T:2014:59 and Judgment of the Court of Justice of 22 October 2015 in Case C-194/14P, AC-Treuhand AG v European Commission, ECLI:EU:C:2015:717.

${ }^{30}$ Decision COMP / 38589 - Thermal stabilizers, of 11 November 2009.

31 This position had already been adopted by the Court of First Instance in its Judgment in the first case involving $A C$ Treuhand, in exactly the same manner. Cf. Judgment of the Court of First Instance of 8 July 2008 in Case T-99/04, AC-Treuhand AG v. Commission of the European Communities, ECLI:EU:T:2008:256, para. 130.
} 
concerted practice on the basis that it reduces the strategic uncertainty of the market for all competitors. Recipients of strategic information are presumed to have accepted the information and adapted their market conduct accordingly, unless they respond with an unequivocal declaration that they do not want to receive such information. ${ }^{32}$

Disclosures of future information that is already public (e.g. through the press or the company's website) do not raise anti-competitive concerns, unless it is proven that this behaviour is strategic and intended to allow competitors to coordinate their behaviours. ${ }^{33}$ According to the Guidelines, the existence of a concerted practice cannot be ruled out, for example, in the event that a public announcement published in a newspaper is followed by public announcements of other competitors with strategic information readjusted for illicit purposes.

The Commission's recent decision from 7 July 2016 in the Container Shipping case illustrates the Commission's approach. ${ }^{34}$ In its investigation, the Commission found that the parties active in the maritime transport sector regularly announced their intended (future) price increases for deep-sea container liner shipping services, at least on routes from Far East Asia to Northern Europe and the Mediterranean (westbound), on their websites, via the press, or in other ways. These announcements indicated the amount of the increase in US-Dollars per transported container unit (twenty-foot equivalent unit, 'TEU'), the affected trade route and the date of implementation. Such announcements are widely known in the industry as 'General Rate Increase Announcements' or 'GRI Announcements'. They generally concern sizable rate increases of several hundred US-Dollars per TEU. GRI Announcements were made typically 3 to 5 weeks before their intended implementation date, and during that time, some or all parties announced similar intended rate increases for the same or similar routes and for the same or similar implementation date. In its Preliminary Assessment of 26 November 2015, the Commission expressed concern that GRI Announcements could be of little value for customers and, more importantly, that this practice could allow the parties to explore each other's pricing intentions and to coordinate their behaviours. This practice may have enabled the parties to 'test', without incurring the risk of losing customers, whether they could reasonably have implemented a price increase and thereby may have reduced strategic uncertainty for the parties and diminished the incentives to compete. The Commission was concerned that this conduct may have amounted to a concerted practice in violation of Article 101 TFEU. The case was eventually closed following the provision, by the parties, of various commitments deemed adequate to neutralise the Commission's concerns (in essence, the parties proposed not to publish and communicate GRI notices, that is, price changes expressed solely as the amount or the percentage of the change).

\section{Assessment of information exchanges under the Commission's Guidelines}

Information exchanges will be assessed, from a competition perspective, on the basis of the type of information exchanged, the nature of the exchange and the prevailing market characteristics.

\footnotetext{
${ }^{32}$ Cf. para. 62 of the Guidelines.

${ }^{33}$ Cf. para. 63 of the Guidelines.

${ }^{34}$ Case AT.39850, decision published in OJ C 327/4, 6.9.2016.
} 


\subsection{Infringements by object}

Article 101 of the TFEU distinguishes between infringements "by object" and infringements "by effect". According to settled case-law, once the Commission has established that an agreement has the object of restricting competition, it does not need to prove the existence of anti-competitive effects. ${ }^{35}$ By contrast, infringements by effect require the Commission to demonstrate that the agreement in question would have actual or potential restrictive effects on competition. The distinction is thus important in terms of evidentiary standards and the burden of proof.

Pursuant to the Guidelines, the exchange between competitors of individualised data regarding intended future prices or quantities constitutes a restriction of competition by object. ${ }^{36}$ There is no need, in this case, to prove actual or potential effects on competition. Once this kind of information has been exchanged, it is extremely difficult for the companies that took part in it to justify their conduct. ${ }^{37}$ It is unlikely, in these circumstances, that the parties to this exchange will be able to prove that potential efficiency gains (e.g. benchmarking) are sufficient to offset the increased risks of facilitating a collusive outcome. Moreover, it would most probably be considered that the same efficiencies could be achieved by less restrictive means, not entailing the exchange of such sensitive and strategic information. The Guidelines add that this type of information exchange can in itself be seen as a cartel practice and, consequently, can be fined as such.

One of the most notable Commission decisions on direct information exchanges between competitors, and one that has gained greater prominence among both commentators and academics, targeted the fruit retailing industry and a number of banana producers by implicating them in a cartel practice. ${ }^{38}$ According to the Commission's decision, the importers of the leading banana brands repeatedly sought to set the reference prices which would be applicable in the subsequent week for their bananas and to announce them every Thursday morning. On several occasions, there were bilateral telephone calls between the companies, usually on the day before they set their price, in which they mutually discussed or disclosed their price intentions: the way they perceived price evolution and/or intended to maintain, increase or decrease

\footnotetext{
${ }^{35}$ See, inter alia, the Judgment of the Court of Justice of 13 July 1966 in Case 56 and 58/64, Consten and Grunding v. Commission, ECLI:EU:C:1966:41, p. 344.

${ }^{36}$ Cf. para. 74 of the Guidelines.

37 See in this regard the Note by Jorge Padilla in the OECD's Policy Roundtable - Information Exchanges Between Competitors under Competition Law of 11 July 2011. The author states that he does not see how it would even be possible in practice to justify information exchanges which are deemed by the Commission to constitute infringements by object, since in such a case the parties involved would be obliged to demonstrate that the exchange does not have "the potential to restrict competition" (see pp. 441 and 442). According to Padilla, this would be an impossible task since the Commission presumes that any communication that constitutes an object infringement is bound to affect the conduct of the undertakings in the market and, therefore in the author's opinion, has the potential to restrict competition. The author cites a Commission decision in which it states that it is not sufficient to show that the practice in question pursued a legitimate aim; that the exchange was of no use to the parties; that the information was public or that it had no anti-competitive effect (see p. 442, with further reference to Case COMP/39188 - Bananas, 15-X-2008 paras. 234 to 236). Padilla concludes by stating that "the only way to show no impact on conduct would be to show that the information exchange was no more than a divertimento among dilettante employees" (p. 442). The author also mentions, as an additional problem, the Commission's wide margin of discretion when assessing any potential efficiencies - a prerogative, in his view, often used to reject the evidence submitted to it by the parties without rigorous analysis (p. 443).

${ }^{38}$ Case COMP/39.188 - Bananas, Commission decision of 15 October 2008.
} 
prices. The Commission treated these practices as a price fixing cartel and imposed fines on the undertakings Dole and Weichert in a total amount of EUR 60.3 million. The decision was upheld on appeal by the Court of Justice who held that "the General Court was able ... to consider that, without making any error of law, the Commission had reason to conclude that price-fixing communications, by reducing each party's uncertainty with regards to the foreseeable behaviour of competitors, were intended to lead to conditions of competition which did not correspond to normal market conditions and had therefore led to a concerted practice which aimed to restrict competition as it is defined in Article 81 EC' (emphasis added). ${ }^{39}$

More recently, it is also important to make reference to the ETURAS case, where the ECJ argued that Article 101 (1) of the TFEU should be interpreted as meaning that the concept of a concerted practice covers the situation where several travel agencies use a common online travel booking system, and that system's administrator posts a notice informing its users that, following the proposals and wishes of the undertakings concerned, the discounts applicable to clients will be restricted to a uniform maximum rate, this notice being followed by technical restriction on the choice of discount rates available to the users of the system. The undertakings which become aware of that illicit initiative and continue to use the system, without publicly distancing themselves from that initiative or reporting it to the administrative authorities, are liable for participating in that concerted practice. ${ }^{40}$

Since the adoption of the Guidelines, a significant number of decisions by national competition authorities in Europe have been adopted, finding that information exchanges constitute an infringement by object and imposing significant financial penalties. In March 2011, for example, the Bundeskartellamt imposed a total fine of EUR 38 million on Kraft, Unilever and Dr. Oetker for having adopted a practice which consisted of informing each other on the state of negotiations between their companies and several major retailers on a regular basis. This exchange concerned information on price increases that they planned to impose on those retailers. ${ }^{41}$ In Spain, the Comision Nacional de la Competencia imposed fines on eight companies active in the professional hair care products sector (among them L'Oréal, Wella and Colomer) in a total amount in excess of EUR 51 million for having been involved in an exchange of sensitive information, which enabled them to study their competitors' future strategies regarding, inter alia, their pricing policy. ${ }^{42}$ Also in Belgium in 2012, the College of Competition Prosecutors made formal allegations against core consumer goods manufacturers and an industry association for having exchanged sensitive information regarding future price intentions. ${ }^{43}$

In the United Kingdom in 2011, the OFT adopted the most restrictive approach proposed in the Guidelines with regard to bub-and-spoke agreements and applied it in the Motor Insurers and Dairy cases, disregarding the precedent set in the Argos case.

In the Dairy case, the OFT concluded that some supermarkets and cheese producers had infringed competition law by coordinating an increase in the prices

\footnotetext{
${ }^{39}$ Judgment of the Court of Justice of 19 March 2015 in Case C-286/13P, Dole Food Company Inc. and Dole Fresh Fruit Europe v European Commission, ECLI:EU:C:2015:184, para. 134.

${ }^{40}$ See Judgment of the Court of Justice of 21 January 2016 in Case C-74/14, "Eturas" UAB and Others v. Lietuvos Respublikos konkurencijos taryba, ECLI: EU:C:2016:42, para. 50.

${ }^{41}$ See the Bundeskartellamt's press release dated 17 March 2011: www.bundeskartellamt.de/SharedDocs/ Meldung/EN/Pressemitteilungen/2011/17_03_2011_Hema.html.

${ }^{42}$ Cf. El Mundo article: http://www.elmundo.es/elmundo/2011/03/03/economia/1299155780.html.

${ }^{43}$ See the press-release: http://economie.fgov.be/en/binaries/20120313_Press\%20Release_tcm327166260.pdf.
} 
paid by consumers for certain dairy products, and imposed fines of almost GBP 50 million. Supermarket chains (the best known including Tesco, Sainsbury's and Safeway) communicated their intentions regarding the pricing of these products to each other, indirectly through the aforementioned dairy producers.

In the Motor Insurers case, the OFT closed the proceedings and declared the commitments offered by the insurance companies binding. These companies provided their future price information on a monthly basis to certain software product providers who later incorporated this information into insurance quote engines accessible by insurance brokers. The OFT considered this exchange of information to be legitimate, since brokers needed access to detailed price information in order to be able to quote insurance prices to their customers. However, the same information was also made available for incorporation into a market data analysis product that allowed brokers to compare the prices charged by all insurance companies. The fact that most of these companies were vertically integrated and therefore also active at the broker level, allowed them access to individual (and detailed) information regarding their competitors' pricing policies (in addition, the information on prices was available for consultation two weeks before it became effective). The OFT considered that this second exchange of information constituted an object infringement and that consideration of effects was unnecessary.

The sensitive nature of the information that was exchanged was critical in the OFT's analysis: it considered that pricing information available through the market analysis product was strategic as insurance companies were able to reverse engineer the pricing policies of their competitors, even before the new tariffs were actually implemented in the market. The OFT also found that the insurance companies knew that the information would be available to their competitors. However, contrary to the Argos Judgment, the OFT did not consider that subjective intention needed to be taken into account and assumed that the insurance companies made effective use of the information obtained to readjust their market behaviours. Under the commitments made binding by the OFT, users of the market analysis product were banned from accessing information on future prices, with only aggregated data remaining available, with averages calculated across at least five UK operators. These commitments show that the nature of the information exchanged was in fact the main criterion underlying the OFT's analysis (in its analysis, the OFT seems to have overlooked the fact that the top 10 insurance companies accounted for a market share of about $70 \%$ ).

\subsection{Infringements by effect}

The vast majority of information exchanges require an assessment of their effects on competition, taking into consideration the specific market context in which they occur, to determine whether they conflict with Article 101 of the TFEU and Article 9 of the Portuguese Competition Act. The "counterfactual" also needs considering. ${ }^{44}$ As mentioned above, the main competition concern presented by information exchanges is whether or not the participating undertakings are able to coordinate their market behaviours. In practice, the question of whether a particular exchange results, or will result, in adverse effects on competition essentially depends on the characteristics of that exchange and relevant market. ${ }^{45}$ The analysis of the impact of a particular

\footnotetext{
${ }^{44}$ See Judgment of the Court of Justice of 28 May 1998 in Case C-7/95 P, John Deere Ltd v. Commission of the European Communities, ECLI:EU:C:1998: 256, para. 29.

${ }^{45}$ In the case of Asnef-Equifax, the Court expressly stated that information exchanges cannot be
} 
information exchange will depend on the determination of how difficult it would be, in its absence, to achieve the desired level of coordination and how the exchange alters that situation.

Once anticompetitive effects have been identified, the information exchange can still be exempted provided that all the requirements of Article 101 (3) of the TFEU (and Article 10 of Portuguese Competition Act) are met: the information exchange should entail efficiency gains that are likely to be passed on to consumers, be indispensable and not eliminate competition.

Benchmarking is a good example of how difficult it is to assess common business practices under EU competition law. The Guidelines acknowledge that benchmarking has a legitimate purpose and that information exchange may enable companies to re-allocate production towards high-demand markets (via, for example, information exchanges about demand) or to low cost companies (through exchanging cost information). ${ }^{46}$ In the mid-1990s, the Commission had already adopted two communications encouraging undertakings to engage in benchmarking. ${ }^{47}$ However, while expressly recognising that benchmarking can lead to efficiency gains, the Guidelines subject benchmarking to the same full assessment as any other information exchange (see criteria below) and strictly limit the type of information exchange that is acceptable. In particular, the Guidelines consider that "an exchange of individualised data would not generally be indispensable". 48

As such, in the Commission's view, benchmarking activities should be limited to the exchange of aggregate information, such as some sort of anonymous industrial ranking or statistical data. The Guidelines even go so far as to question the legality of the exchange of aggregate information in markets with a highly concentrated structure. ${ }^{49}$ It follows, therefore, that the exchange of individualised information can only occur between non-competing companies or in cases where: (i) the market is not concentrated; and (ii) the information exchanged is historical or concerns nonsubstantial aspects of the cost structure of the undertakings. Under these constraints, the added value and commercial relevance of benchmarking can be questioned.

As mentioned above, the Commission's primary concern is whether or not the information exchange can facilitate market coordination - the analysis should therefore take into account the specific market conditions, the type of information exchanged and the nature of the exchange system.

\subsection{Market characteristics}

Since collusion constitutes the Commission's primary concern, it is necessary to assess whether the prevailing market characteristics are such that they enable

assessed in the abstract and that their compatibility with the competition rules depends on the economic conditions of the relevant market, the purpose and conditions of access to the exchange and the type of information exchanged. Cf. Judgment of the Court of Justice of 23 November 2006 in Case C-238/05, Asnef-Equifax, Information Services on Solvency and Credit, SL against the Association of Banking Services Users (Ausbanc), ECLI: EU:C:2006:734, para. 54.

${ }^{46}$ Cf. para. 95 of the Guidelines. This is an aspect also recognised in the OECD document cited above, pp. 10, 24 and 25.

${ }^{47}$ See Commission Communication COM (96) 463 final of 9 October 1996, "Benchmarking the competitiveness of European industry"; and Commission Communication COM (97) 153 final of 16 April 1997, "Benchmarking, Implementation of an instrument available to economic actors and public authorities".

${ }^{48}$ Cf. para. 101 of the Guidelines.

${ }^{49}$ Cf. para. 108 of the Guidelines. 
competitors to collude. Information exchanges would thus be more problematic in markets with only a small number of homogeneous competitors ${ }^{50}$ fairly standardised products, relatively stable demand and supply, ${ }^{51}$ and public transactions. ${ }^{52}$ Barriers to entry ${ }^{53}$ and symmetry in competitors' cost structures ${ }^{54}$ must also be taken into account.

${ }^{50}$ In general, the greater the degree of market concentration, the easier it is to achieve and maintain the terms of coordination. Indeed, where the number of cartel participants is reduced it becomes easier to achieve convergence in relation to the common focal points of coordination, i.e. the likelihood of deviation from the cartel is less likely. On the other hand, the greater the number of participants in the cartel, the greater is the relative gain of the participant who decides to deviate from the terms of the agreement (imagine a market in which two symmetrical companies operate - the deviant cartelist will only succeed in capturing, at best, $50 \%$ of the market, whereas in a market with five operators the cartelist can capture up to $80 \%$ of the market), and the smaller the collusive profits to be shared between the participants. The Guidelines and European case law make it clear that in fragmented markets with a low concentration ratio, the likelihood of an information exchange having restrictive effects is low and more likely to result in efficiencies. In the New Holland Ford case, the Court of First Instance stated in that regard that: "on a truly competitive market transparency between traders is in principle likely to lead to the intensification of competition between suppliers, since in such a situation the fact that the trader takes into account information made available to him in order to adjust his conduct on the market is not likely, having regard to the atomized nature of the supply, to reduce or remove for the other traders any uncertainty about the foreseeable nature of its competitors 'conduct". See Judgment of the Court of First Instance of 27 October 1994 in Case T-34/92, Fiatagri UK Ltd and New Holland Ford Ltd v. Commission of the European Communities, ECLI:EU:T:1994:258, para. 91. In the decision already cited in the UK Tractors case, the Commission considered relevant the fact that four companies participating in the exchange accounted for about $80 \%$ of market share. In support of the Commission's approach, the Court of First Instance observed on appeal that “... general use, as between main suppliers and, contrary to the applicant's contention, to their sole benefit and consequently to the exclusion of the other suppliers and of consumers, of exchanges of precise information at short intervals, identifying registered vehicles and the place of their registration is, on a bighly concentrated oligopolistic market such as the market in question and on which competition is as a result already greatly reduced and exchange of information facilitated, likely to impair substantially the competition which exists between traders". See Judgment of the Court of First Instance of 27 October 1994 in Case T-35/92, John Deere Ltd v. Commission of the European Communities, ECLI:EU:T:1994:259, para. 51. By contrast, in the EUDIM case, the Commission considered that the fact that the market involved more than 3,000 operators would be enough to make it possible to conclude that the exchange under review, which targeted individualised and confidential information on competitors, was not likely to have an appreciable effect on competition. Cf. Notice pursuant to Article 19 (3) of Council Regulation no ${ }^{\circ}$ 17, Case No IV/33.815, 35.842 - EUDIM), OJ nº. C 111/8, of 17.04.1996.

${ }^{51}$ Fluctuations in product prices and quantities may make it difficult to agree on the terms of coordination and to monitor their implementation. In a context of significant sales volatility, a company that loses a significant number of sales may not be able to perceive whether this is due to a normal fluctuation in market conditions or to a deviation by a co-cartelist. Volatility can also impact a company's ability to signal desired target prices.

${ }^{52}$ In the latter case, allowing for the improved monitoring of agreed terms.

${ }^{53}$ In the absence of barriers to entry, participants will find it more difficult to maintain the external stability of the cartel and the terms of coordination. In fact, the artificially inflated prices and the greater profitability associated with the cartel end up attracting new entry and jeopardizing the cartel's effectiveness. If the probability of the cartel not succeeding is high, participating companies will be less concerned about the possibility of future punishment and gain more incentive to deviate. In the UK Tractors case, the existence of high barriers to entry in the UK agricultural tractor market was a decisive factor in the Commission's decision to declare the exchange unlawful.

${ }^{54}$ Asymmetric cost structures generate distinct preferences for coordinating focal prices. The asymmetry in terms of the size of the companies involved and their cost structure may also make it difficult to maintain coordination: it is more difficult to punish companies that are more efficient and less costly than the less efficient ones, and as such the former are encouraged to deviate from coordination. On the other hand, the asymmetry in terms of capacity means that companies with less capacity compared to those with high capacity have less incentive to deviate and less capacity to exercise disciplinary power. This combination makes deviation more appealing to larger-capacity companies. See Marc Ivaldi, Bruno Jullien, Patrick Rey, Paul Seabright, Jean Tirole, "The Economics of Tacit Collusion", Report to the 
However, the analysis cannot be limited to the pre-existing market situation, and should also assess whether the information exchange itself modifies existing market characteristics so as to make collusion possible. ${ }^{55}$

\subsection{Nature of shared information}

The second key criterion is the nature of the exchanged information. More precisely, the assessment of an information exchange agreement depends on whether the information is strategic, aggregated or individualized, historic or recent, and private or public.

The exchange of information that "reduces strategic uncertainty in the markel" is the most problematic. ${ }^{56}$ The Guidelines define "strategic data" in broad terms covering prices, quantities, customer portfolios, production costs, turnover, sales, capacity, quality, marketing plans, risks, investments, $\mathrm{R} \& \mathrm{D}$ programs and their respective results. It is generally understood that information related to prices and quantities has the greatest strategic value, followed by information on costs and demand. ${ }^{57}$

According to the Commission, in non-concentrated markets, an exchange of "genuinely aggregate data", i.e. data "where the recognition of individualised company level information is sufficiently difficult" will not give rise to any competition-related concerns. ${ }^{58}$ In the Wirtschaftsvereinigung Stahl case, the General Court annulled the Commission's decision, essentially considering that the level of aggregation of the information exchanged was sufficient to remove any competition concerns (the information concerned only the sales of the participating undertakings without distinguishing between the different consumer sectors and only allowed for very approximate calculations of the market shares of the parties). ${ }^{59}$ In the Fatty Acids case, the Commission stated that it did not object to an exchange of statistical information between trade associations and reporting agencies, even if it specified individual data, provided that the information exchanged did not enable the recipients to identify the competitors in question. ${ }^{60}$ Also in the European Wastepaper Information Service (EWIS) case, the Commission eventually validated

European Commission's Directorate-General for Competition, 2003: http:/ / ec.europa.eu/competition/ mergers/studies_reports/the_economics_of_tacit_collusion_en.pdf.

${ }^{55}$ Cf. para. 77 of the Guidelines.

${ }^{56}$ Cf. para. 86 of the Guidelines.

${ }^{57}$ Information on raw material costs is less likely to be perceived by competition authorities and courts as strategic. It will be the case, however, when these costs are directly correlated with the price and allow competing firms to identify the prices of their rivals. In the EUDIM case, the Commission authorised an exchange between members of a trade association which concerned confidential information on the purchase cost of several different products. The parties argued, and the Commission agreed, that exchanging this information would have the effect of increasing the bargaining power of its members vis-à-vis their suppliers, reducing costs and thereby increasing the degree of competition in the market. In the T-Mobile case (Case C-8/08), already mentioned, the Dutch mobile operators met to discuss the need to reduce the fees paid to their dealers for new clients brought to their respective networks. In this context, the mobile operators exchanged information on the value of the fees they paid to such dealers. Although it could be argued that these fees amounted to mere input costs (being, therefore, less sensitive from a competition law perspective), their payments enabled those dealers to reduce the price charged to consumers for mobile phones, meaning that there was, in fact, competition among the mobile operators in relation to those fees. This led to the conclusion that fees were a key competitive parameter.

${ }^{58}$ Cf. para. 89 of the Guidelines.

${ }^{59}$ See Judgment of the General Court of 5 April 2001 in Case T-16/98 Wirtschaftsvereinigung Stabl et al. v. Commission, ECLI:EU:T:2001:117, para. 52.

${ }^{60}$ See Case IV/31.128, Fatty Acids, para. 35. 
an information exchange after EWIS confirmed that only aggregate information would be exchanged and that the number of parties involved exceeded four, thus not allowing the identification of each of its members. ${ }^{61}$ The rule of information exchange between a minimum of four market players was again applied by the Commission in CEPI-Cartonboard. ${ }^{62}$ The Commission had initially objected to an aggregate exchange of information concerning countries where there were fewer than three competitors and had demanded that it be aggregated with information from other countries in order to accommodate a larger number of competitors and prevent the individual identification of competitors.

The Guidelines put forward the notion that an exchange is deemed to be problematic once it becomes possible to detect a deviation from a potential collusion framework, even though it may not possible to specifically identify the deviating company. ${ }^{63}$

The Guidelines also propose that the exchange of "bistoric information" is not, in principle, likely to lead to collusive results. It can be read that data "can be considered as historic if it is several times older than the average length of contracts in the industry if the latter are indicative of price re-negotiations". ${ }^{64}$ There is, therefore, no pre-defined threshold at which point data is deemed to be historic, that is to say, old enough not to raise competition concerns. Whether data is to be considered genuinely historic will depend essentially on the specific characteristics of the relevant market and, in particular, on the frequency of price renegotiations in the sector. Information becomes historic more rapidly in unstable markets. The Guidelines also suggest that, in this respect, the nature and aggregation of information must also be taken into account - and as such the age of data cannot constitute an independent criterion for analysis.

In the aforementioned CEPI-Cartonboard case, the Commission took the view that the information compiled by a trade association relating to aggregate data for the previous four weeks, which did not concerned prices, production or capacity, could be considered as historic. ${ }^{65}$ However, the validity of this assertion will be of little value in industries which exhibit different characteristics and in which contractual practices are different. Consequently, for example, in both the UK Tractors and Wirtschaftsvereinigung Stahl cases, the Commission considered that one-month old information should be considered, for the purposes of the exchanges in question, as recent. An analysis on a case-by-case basis is therefore always required.

The Guidelines also state that "genuine public information exchanges are unlikely to constitute an infringement of Article 101". However, this concept is defined very narrowly, as information that "is generally equally accessible (in terms of costs of access) to all competitors and customers. For information to be genuinely public, obtaining it should not be more costly for customers and companies unaffiliated to the exchange system than for the companies exchanging the

\footnotetext{
${ }^{61}$ Cf. Notice pursuant to Article 19 (3) of Council Regulation $n^{\circ} .17$ concerning an application for negative clearance or exemption pursuant to Article 85 (3) of the EEC Treaty - Case No IV/32.076 - European Wastepaper Information Service.

${ }^{62}$ Notice pursuant to Article 19 (3) of Council Regulation No 17 concerning an application for negative clearance or exemption pursuant to Article 85 (3) of the EEC Treaty - Case No IV/34.936/ E1 - CEPI-Cartonboard.

${ }^{63}$ The OFT adopted this same approach in Motors Insurers, requiring that the information provided by the market analysis product be displayed in terms of average percentages between categories of competitors.

${ }^{64}$ Cf. para. 90 of the Guidelines.

${ }^{65}$ See Commission Note in Case IV/34.936/E1, CEPI-Cartonboard [1996], OJ C 310/3.
} 
information" " ${ }^{66}$ It is therefore not sufficient for the information in question to be in the public domain. In deciding whether the information is public or private in nature, it is also necessary to take into account the cost of obtaining it. Even if the data exchanged between competitors is what is often referred to as being "in the public domain", it is not genuinely public if the costs involved in collecting the data deter other companies and customers from doing so.

In the TACA case, the Court of First Instance examined, amongst others aspects, an exchange of information between shipping companies in relation to their contractual terms of service. ${ }^{67}$ The court ruled in opposition to the Commission, arguing that, at the time of the infringement, the information in question was in the public domain by virtue of the United States legislation which required its publication. ${ }^{68}$

\subsection{The nature of the exchange system - the issue of frequency}

Frequent exchanges of information raise potentially greater problems from a competition law perspective, increasing the likelihood of coordinated behaviour. ${ }^{69}$ A more frequent exchange of information reduces both the time period necessary for rival competitors to understand the signal sent, and the time period necessary for the detection and punishment of a deviating cartelist. However, the frequency of the information exchange must always be analysed in light of the structure of the market in question and the nature of the shared information, i.e. the analysis must be specific to the situation at hand. In unstable markets, for example, which are often characterized by short-term contractual cycles, successful collusion will necessarily require a more frequent exchange of information.

The Guidelines consider an exchange system to be genuinely public if the data exchanged is equally accessible (in terms of the cost of access) to all competitors and customers. The Guidelines also note that information being exchanged publically reduces the probability of collusive behaviour in the market, although it does not completely rule out the possibility.

\section{Preliminary conclusion}

The broad scope of the Guidelines covers all types of information exchanges between competitors, whether direct or indirect. While it is true that the exchange of individualised information on future prices or quantities is a hardcore practice which can be regarded as creating a cartel and is therefore punishable by the imposition of high-value fines, the Guidelines also recognise that information exchanges are common practice and take place in many pro-competitive markets and may contribute to a better competition dynamic. Therefore, the competition analysis of information exchanges should be made on a case-by-case basis, taking into consideration the type of information exchanged and the prevailing market characteristics.

Although the approach of the Commission and the EU Competition Authorities

\footnotetext{
${ }^{66}$ Cf. para. 92 of the Guidelines.

${ }^{67}$ Judgment of the Court of First Instance of 30 September 2003 in Joined Cases T-191/98, T-212/98 to T-214/98, Atlantic Container Line AB and Others v Commission of the European Communities, ECLI: EU:T:2003:245.

${ }^{68}$ Ibid. para. 1154 e ss.

${ }^{69}$ See also Marc Ivaldi, Bruno Jullien, Patrick Rey, Paul Seabright, Jean Tirole, "The Economics of Tacit Collusion", Report to the European Commission's Directorate-General for Competition, 2003: http:// ec.europa.eu/competition/mergers/studies_reports/the_economics_of_tacit_collusion_en.pdf.
} 
is restrictive (heavily influenced by ECJ case-law, in particular following the ECJ ruling in the bananas case) and leaves several questions unanswered (due to certain imprecisions in some criteria), we cannot conclude that competitors are prevented from conducting their business through cooperation and/or integration projects. In the latter case, by advancing with preliminary contacts and exchanges of information which can be objectively regarded as indispensable to the execution of transactions aimed at the acquisition of competing undertakings or the ex-novo creation of entities under the joint control of two or more competing undertakings - so long as the rules that stem from the analysis carried out in Chapter I are complied with, so as not to compromise the fundamental principle of strategic self-determination of market conduct, before the transaction is completed or in case it does not proceed. Let us see how.

\section{Information exchanges in the context of a merger transaction}

\section{Introductory remarks}

Chapter II seeks to offer a concrete expression to the general doctrine explored above in Chapter I in the specific situations of premature exchanges of sensitive information between competing undertakings prior to the conclusion of a merger transaction, and the adoption by the competent competition authority (Commission or PCA) of a clearing decision affirming its compatibility with competition law. The exchange of sensitive information between two competing undertakings in the context of such a procedure, and prior to the adoption of the clearing decision, may be interpreted by a competition authority, in addition to potentially constituting cartel behaviour, as "gun jumping" and could, consequently, expose the participants to potential sanctions (maxime, fines and the possibility of being liable to damages in legal proceedings against aggrieved parties). ${ }^{70}$

Chapter II identifies the competition law rules that should govern the business conduct of the participating companies within the critical relevant time frame: between the signing of the contract (often preceded by the adoption of a Memorandum of Understanding ("MOU")) and the date of the implementation of the transaction, after obtaining the clearance decision of the competition authority. We will see that the same principles (i.e. the need for caution) apply with equal force during the negotiations leading up to the signing. Also, that there are circumstances, even after the transaction is implemented, in which the parties must adhere to the same rules.

As a general rule, it is legitimate for the parties to take all necessary initiatives to advance the proposed transaction and the projects to integrate their businesses, provided that: (i) no implementation behaviour takes place prior to obtaining the necessary merger control approvals; and (ii) any exchange of competitively sensitive information, prior to closing, is carried out in accordance with the principles set out

\footnotetext{
${ }^{70}$ This was the case in 2007 in the context of the Commission's analysis of the merger between Ineos and Kerling, two competitors in the PVC market (Case COMP/M.4734). During the second phase of in-depth investigation, the Commission became aware that these companies had already adopted several implementation steps in breach of the standstill obligation, as per Article 13 of the Regulation (EC) $n^{\circ}$. 139/2004, of 20 January 2004. Among other things, the Commission found that Ineos, the acquirer, had intervened in the management of the target by appointing personnel to its staff and giving instructions concerning the company's operations. With particular interest to the point under discussion, the Commission also found that the companies had exchanged sensitive information concerning the operations of both parties.
} 
below.

The merging parties should limit the disclosure or exchange of non-public, competitively sensitive information to a previously identified core group of individuals (the so-called "clean team") whose knowledge of such information is objectively indispensable to the execution of the transaction, and ensure that the information transmitted, whether qualitative or quantitative, is restricted to that which is absolutely instrumental to reaching the terms of the agreement or for valuation or organisational purposes.

The clean team should be identified separately by both parties and include external and independent consultants (e.g. accountants/lawyers) in order to ensure that any exchange of information occurring prior to closing is conducted in a secure manner and in accordance with the rules governing competition. The reporting actions of this team must be carried out according to the criteria set below. It must not be forgotten that these same rules of competition also apply to integration planning between the parties before the acquisition has closed. Accordingly, the parties are prohibited from fully implementing any integration plans or otherwise coordinating their present or future business activities prior to closing, particularly since the acquisition needs to be notified to a competition authority.

It is imperative that, in the course of the proceedings, the parties continue to view each other as competitors, at least until the transaction is closed. It should be clearly understood at the outset of all discussions that if the transaction is not finalised, the two companies will continue to act as independent competitors (there should be no agreement or common understanding whatsoever between them concerning their respective future independent operations in the market). As such, the participants should continue to conduct business with complete independence and strategic autonomy as if the merger or joint venture were not contemplated at all. Neither company should seek to influence the business decisions of the other beyond what is absolutely necessary to protect its interests between signing and closing pursuant to the relevant agreement.

Competition law authorities (the Commission or the PCA) would be concerned if wide-ranging sensitive information took place prior to signing between two distinct and independent competing companies. They would be particularly concerned as to what could happen if the transaction is not finalised; in such a case, the information exchanged by the competing companies could (depending on the extent of information exchanged) facilitate the fixing, stabilising or coordination of future prices, rates or terms of trade, as well as the sharing of customers and markets. As such, the parties should limit the disclosure or exchange of competitively sensitive information to what is effectively indispensable for deal negotiations and integration planning. Any such exchange or exchanges should be proportional, in qualitative and quantitative terms, to the progress being achieved by the parties towards closing the transaction.

\section{Specific guidance}

\subsection{The treatment of sensitive information}

In Chapter I of this article, it was noted that, as a general rule, competition law concerns most obviously apply to exchanges of information concerning current or future prices, customers and markets in which the parties are both present. This is considered to be the most sensitive type of information from a competition law 
perspective. However, the rules on the exchange of sensitive information between competitors also apply to any information that may change how one company might price or perform in the future, for example, the exchange of proprietary information regarding costs, product offer development plans, marketing strategies, unannounced development plans, detailed customer information, specific product or market plans, non-public R\&D plans or strategies, intellectual property rights and information on trading partners (e.g., supplies or distributors).

As such, the first step is to assess the information and determine whether it is likely to be considered as competitively sensitive.

At this stage, the buyer is usually allowed access to a significant amount of confidential information from the target company. In some cases, information sharing may be bidirectional, with the target company also receiving confidential information from the buyer (e.g. for the purpose of a joint synergies assessment).

Normally, before a due diligence commences, the parties will sign a confidentiality agreement prohibiting the unauthorized use of shared confidential information and its disclosure to any third parties. However, while such agreements may be sufficient for the purpose of ensuring that information is effectively treated as confidential vis-à-vis third parties, in cases where the parties are current or potential competitors, the mere exchange of that information may in itself result in a competition law infringement. In short, confidentiality agreements are insufficient to ensure compliance with competition law. For this reason, and given that bidders will always need sufficient information to evaluate the target, it is necessary to resort to other mechanisms that allow for the chances of an infringement to be minimised.

In situations where the parties believe that the information to be shared is sensitive from a competition perspective, they need to consider two alternatives: (i) the simple refusal to share the information in question - this solution poses the least risk but may conflict with the buyer's intention to gain access to information that it believes to be crucial to its assessment of the target. The seller may opt for a staged disclosure arrangement, with limited information provided to the wider pool of bidders, and more detailed information only provided to a preferred bidder when it is clearer that the transaction will go ahead; or (ii) the adoption of a procedure to ensure that recipients of the sensitive information are not able to use it in a way that would affect their behaviour in the market.

The second option involves limiting the number of individuals who will be exposed to the sensitive information. This is achieved in the vast majority of cases through the creation of a clean team.

\subsection{Communications should be limited to a clean team}

During the due diligence phase, between signing and completion, all communication and disclosures should be limited only to those particular individuals who are involved in the deal discussions or integration planning, and then only on a need-to-know basis. These individuals should be specifically identified (as a "clean team"). The number of individuals forming the clean team should be kept to a minimum. The members of the clean team should be non-operational personnel. Use of marketing or other operational business people engaged in day-to-day operations of the parties should be excluded. Often, the clean team will include personnel from the acquiring party, but who do not perform functions related to sales, marketing or any other strategic parameters of the company. The safer option, however, is to employ a 
third party advisor to receive the sensitive information on behalf of the receiving party and to draw up a final report informing the receiving party of the non-competitively sensitive conclusions reached.

As a cautionary measure, it is advisable to require each member of this team to sign a confidentiality agreement identifying the potential problems and sensitivities from a competition perspective and limiting the use and sharing of the information received. The parties to the transaction should also ensure, through the adoption of written rules to that effect, that none of the members of the clean team are in a position to influence the commercial behaviour of the recipient party for as long as the sensitive information to which he/she has been exposed remains sensitive. The process of filtering the information to be shared and agreeing with the other parties involved as to how sensitive information should be dealt with may take some time. The parties should be aware of this constraint in order to prevent the deal schedules from pressuring them into adopting non-compliant behaviour.

\subsection{Reporting on the analysis of sensitive data}

Communications between business people should be handled in a manner that minimises any implication of improper communication, e.g. through use of preapproved procedures, written requests, with the involvement of or at the request of third parties such accountants, management consultants or legal counsel. Companies should, whenever possible, use external and independent third parties for the purpose of collecting and analysing the most sensitive data (e.g. accounting firms, consultants or external lawyers).

This means, in particular, that the clean team is authorised to report on their findings, but that this report must comply with the following guidelines: i) it is legitimate to disclose sensitive information, provided it is aggregated and historic and does not influence the parties' current or future decisions regarding the commercial policies they intend to implement in the market, especially at the pricing level; (ii) references in the parties' contracts to the names of their customers and suppliers should always be deleted (unless they have already been disclosed in relation to the specific contract), or alternatively, relevant issues should be summarised without reference to specific suppliers or customers; iii) all references made to names, trademarks, brands or other information that facilitates individual identification must be deleted; (iv) adoption of certain rules for the dissemination of sensitive information in a more generalised form - the exchange of cost-related information, for example, should remain at a higher level of segmentation (e.g. average total costs) and information on prices, volumes or capacity should be offered in "ranges" or in statistical format, rather than individualised; and (v) as a general rule, the report should communicate the nature of a question or a problem, as opposed to providing details (e.g., make generic reference to "future strategic problems").

The exchange of the most sensitive categories of information should normally be made in writing and to the clean team rather than in face-to-face meetings, which, together with telephone calls, create the additional risk of reconfiguring the exercise of information exchange from a legitimate instrument of due diligence to an activity of collusive purposes. If it is necessary to hold face-to-face meetings to exchange information (e.g., because it can only be explained orally), it is advisable to have external legal advisors present so that they can monitor and record all the exchanges effected - thus permitting the parties ex post to resort to a written report that proves that the 
exchange of information did not exceed the strict limits provided by competition law.

\subsection{Issues that might be subject to sharing outside of the clean team}

Outside the clean team, it is permissible to discuss questions/issues that are deemed necessary for the successful completion of the transaction and whose sensitivity is mitigated, including, in particular, financial and tax information; expected overall profitability from general product lines (in contrast to specific product price policy); information related to corporate IT systems, accounting methods and information management; information on regulatory compliance; physical description of facilities; the value of certain corporate assets; the number and names of relevant employees, current job description (information on salary, including other employment benefits, may be exchanged, preferably in aggregate form, as long as it is necessary to complete the transaction); information on human resources; and communication with media or employees. As a general rule, it is also legitimate to share historical information on tax returns, company balance sheets, and information on labour, tax, environmental, or health and safety issues.

To reiterate, in contrast to the type of information referred to above, sensitive commercial information should never be shared outside the clean team, and the most strategic and sensitive type of information should preferably be managed by independent third parties (external accounting or consulting firms and external lawyers) included in the clean team. The clean team should report on their findings in accordance with the criteria outlined above.

\subsection{Integration planning and other coordinating phases prior to completion}

Once the due diligence has been completed, before closing occurs, parties may wish to share information as a preliminary stage to the integration of their business. At this stage, the parties still remain independent competitors, so special care must be taken to ensure that competition laws are not infringed.

In principle, and as general guidelines, in the phase prior to the completion (which, as mentioned, always has to be preceded by the express or tacit authorisation of the transaction by the competition authority), the parties are not allowed to: share strategic information as laid out in Chapter I of this article; manage or influence the other's business affairs by taking over management control (i.e. it is not permissible to influence management decisions of other parties beyond that which is strictly necessary to protect the company's interests before closing, for example by stipulating a prohibition on contracting debts of an objectively unjustified and disproportionate amount, mortgaging strategic company assets, causing unjustified collective redundancies, etc.); integrate, in any other way, any operations of the parties (including the transfer of personnel from one undertaking to another); coordinate any practices, decisions or strategies relating to basic competitive parameters such as prices, volumes, capacities, marketing strategies, etc.; coordinate, in general, the competitive behaviour of the parties (in particular, the parties should not share common contacts, including common account managers, with respect to shared customers, and should not terminate the production of certain goods or services, or introduce new goods or services, as a result of any coordination carried out between them); develop common marketing activities (in particular, the parties should not adopt common marketing policies or take common advertising initiatives, nor allocate markets and/or customers among themselves); coordinate R\&D activities; or enter into agreements or commercial partnerships with each other, other than at an 
arms-length basis.

At this stage, parties should also consider the use of confidentiality agreements in order to limit access to sensitive, strategic and confidential information to the individuals who actually need the information for integration planning purposes and should not allow it to be used for commercial purposes (in situations of information leakage). As with the formation of the clean team during the negotiation phase prior to signing, the individuals from the parties who will be granted access to sensitive information during pre-closing integration planning should be identified and, preferably, added to the clean team. Personnel involved in integration planning should, as a general rule, be personnel who are involved in the strategic planning activities of both parties rather than purely operational staff.

Parties may establish joint-project teams, but their activities should be restricted to planning the post-closing period. The adoption of any implementing measures should always be avoided. The use of external and independent legal advisors to manage the documents shared between the parties and supervise the planning of the operation is always recommended. The parties must also adopt measures that facilitate the destruction or return of documents if the transaction falls through.

\subsection{Following the implementation of the transaction}

In the case of straightforward acquisitions, once the transaction has been authorised and completed, the buyer and the target will become part of the same corporate group and therefore of the same economic unit. They will therefore be authorised, under competition law, to share sensitive information. An exception is made, of course, in the case of the sale of a part of the business and where the seller and the entity resulting from the transaction remain as separate undertakings - in such cases the prohibition on the sharing of sensitive information will continue, expost, to be applicable to both.

The situation may be more complex when it concerns the creation of a joint venture or the acquisition of a minority shareholding that does not grant control over the target.

In the first case, the joint venture should not be used by its parent companies as a vehicle for the sharing of sensitive information. Insofar as the flow of information between a parent undertaking and the joint venture is concerned, what is permissible will greatly depend on the underlying context, in particular whether the parent companies are current or potential competitors of the joint venture and whether the joint venture has been notified to the competent competition authority under merger control rules. In the latter case, it is necessary to consider whether the sharing of the information in question falls within the scope of the clearing decision. Here too, it is imperative to consider safeguard mechanisms that protect parties from a possible breach of competition rules.

In the case of non-controlling minority shareholdings, the buyer and the target remain independent companies. To the extent that these entities can be considered as actual or potential competitors, they will have to continue to ensure compliance with the rules of competition law and, in particular, with the framework prohibiting the exchange of sensitive information. Once again, it is necessary for the parties to put in place procedures to minimize the risk of non-compliance. 


\section{Conclusion}

The sharing of sensitive information between companies that may be considered as actual or potential competitors may attract serious consequences, including the application of high-value fines (with a limit of $10 \%$ of each of the parties' total revenue for the previous year) and the they may be subject to indemnity lawsuits. The parties to a merger must be aware of the applicable competition rules and structure their operations accordingly.

If the transaction is subject to mandatory notification to a competition authority, the contracting parties and their competitors must always follow a fundamental guideline: not to take any initiative that may compromise their competitive position in the event that the transaction fails to proceed. The parties should not coordinate (even informally) their respective business activities. Both should continue to act as if their respective businesses were to continue to be managed in a strategically independent and autonomous manner. The parties shall not, under any circumstances and prior to the transaction being authorised and completed, use sensitive information that they may have received from their counterparty for the purpose of defining their own business management decisions.

Given that breaches of competition law may also result from the conduct of a single employee or associate of the company, the sharing of sensitive information is ultimately a matter of compliance, requiring companies to provide to all individuals involved in their business with appropriate training and to put in place clear and objective procedures as to how sensitive information can be disseminated. 